\title{
Factors affecting the transition of the Polish power system
}

\author{
Wojciech Suwala ${ }^{1, *}$, and Artur Wyrwa ${ }^{1}$ \\ ${ }^{1}$ AGH University of Science and Technology, Faculty of Energy and Fuels, Poland
}

\begin{abstract}
Energy systems face radical -almost revolutionary changes which, however, will be stretched over the long period. The critical factors influencing the future development of the Polish power sector are discussed in this paper. Development of intermittent energy supplies from renewable energy sources imposes a challenge on the entire power system and requires specific adaptations and responses from traditional generation units. Up to the present time they have been used to work in the stable mode while now they need more operational flexibility. The share of RES constantly increases. On one hand, this has a very positive environmental impact, but on the other it disturbs economics of classical generation units. Also liberalized electricity markets are impacted and the risks in power investments have increased. The capacity market could constitute a remedy, which will incentivise the investments necessary to fill the gap created by closing exhausted and inefficient plants. On the consumer side electromobility could change the demand, not only in quantity but also in terms of load profile. Climate policy tends to detriment coal based generation. For countries abundant in coal resources which make use of this cheap fuel, such as Poland, the question arises about its future role. Even in the most coal-supportive scenarios revised in this paper its relative share in electricity generation does not exceed $50 \%$ in 2050 while in others it rather goes much below $30 \%$. .
\end{abstract}

\section{Introduction}

The fuels and energy sectors undergo significant changes of various nature, changes that have never been observed up to the present. They come from the development of technologies and policies. The regulated monopoly structures have been unbundled, deregulated and became subject of market forces. Liberalization resulted in lowering electricity price for the final users, and thus also lowered the costs of production in manufacturing and households sectors [1]. The development of renewable energy sources has affected both energy supply- and demand- sides. The support that has been given to renewables resulted in significant increase of their capacities [2]. Investment subsidies and very low, if any, fuel costs favours RES technologies with the current design of the electricity markets [3]. As a result the traditional base load generation plants including, nuclear, fossil fuel and large hydro (when not supported by renewable energy tariffs or

\footnotetext{
* Corresponding author: suwalaw@agh.edu.pl
} 
other market mechanism) are disadvantaged. Power companies have started to work in an uncertain environment of changing prices of their product. It has led to the reluctance in new investments and increased the risk of possible power shortages in the future. The undispatchable nature of variable renewable energy (VRE) like wind and PV have also a major impact on the total power system that other plants have to compensate for to adapt to the power demand. Their capacity factor is also much lower than for classical base load sources and their production is intermittent and non-controllable. As a consequence the operation of traditional thermal units has become more and more irregular as they need to cover only a residual load demand, what also leads to a drop in efficiency and higher emissions. Also in periods of high RES supply production can be higher than the demand what forces producers to lower prices even to negative level from units which could not be stopped. That is the reason for lots of studies aimed at improving energy system flexibility e.g. [4]. To overcome the problem of renewing controllable electric capacities new market instruments were introduced in the form of the capacity market, i.e. certain remuneration for supply guaranty [5]. This should compensate for the price uncertainties for power investors. Another important factor affecting the supply side are environmental regulations which are periodically revised and result in increasingly stringent emission limit values for air pollutants [6]. The demand side is also changing. On one hand, end use technologies need to meet energy efficiency standards and are becoming more efficient e.g. lighting is based on energy efficient LED lamps, home utensils of improved energy efficiency contribute to lower consumption. On the other hand, the increased living standard results in higher penetration of electric devices. Maintaining working comfort in the summertime with increasing temperatures leads to growing number of air conditioners and consequently an increase in demand. This makes the change in the seasonal load patterns as summer used to be a period of lowest demand, giving time for maintenance and modernisations. Transport sector is gradually becoming electrified. Without doubt Polish energy sector needs to adjust to these new conditions and the question is rather how quickly its transformation can be achieved. The historical evidence shows that changes in the fuels and energy sectors have had an evolutionary character. The time needed for a new energy supply and energy end-use technologies to achieve widespread market deployment ranges from 20 to almost 70 years and this also should not be overlooked [7].

\section{Factors affecting energy systems development}

The following parts refer to the identified factors, which will shape the future of Polish Energy sector.

\subsection{Change of the load patterns}

The capacity demanded in each hour of the year (or day) can be sorted according to its frequency of occurrence and visualized in the form of the system load-duration curve. Traditional load curves observed in the past had three levels that could be clearly distinguished. The peak level included the periods with the highest load which typically occurred ca. $20 \%$ of time in a year. Similarly, the lowest level included ca. $20 \%$ of the time with the lowest load. The intermediate level included the load that occurred in between. The present load duration curves, however, become more linear (Fig. 1). Randomly selected cases, which are presented in the figures below are good examples. There are differences in the shapes between weekend and working days. The increase in the load between 2015 and 2018 is also visible. In case of weekends it is only ca. 3.5\% while for working days it is up to $5.6 \%$. 


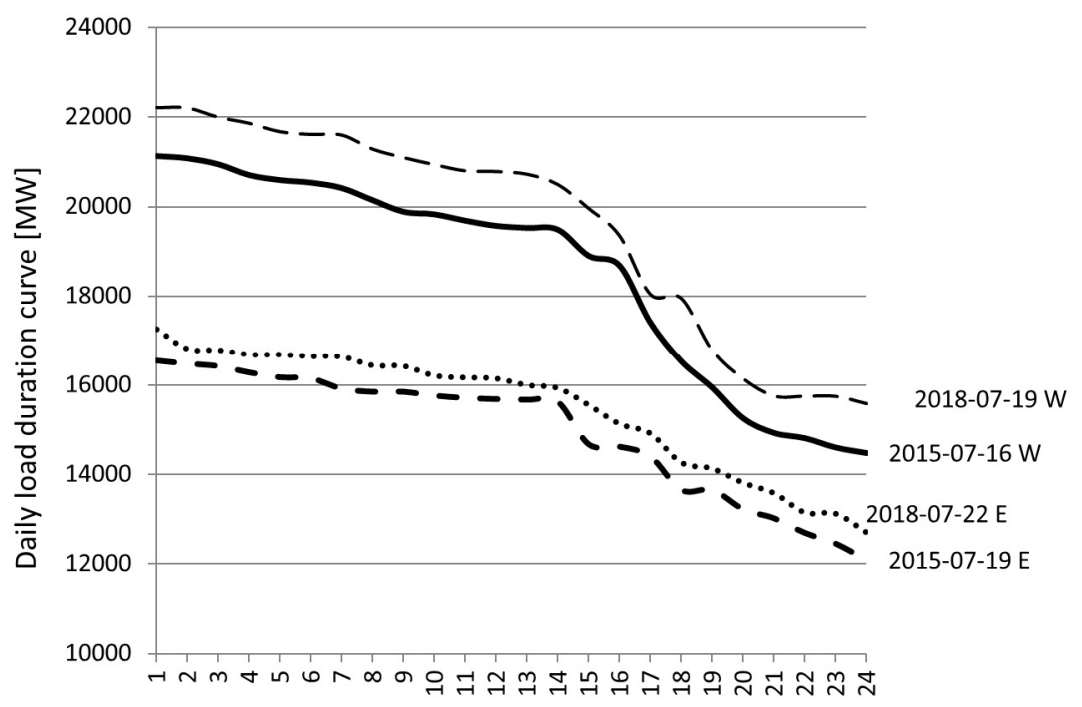

Fig. 1. Load curves for selected weekend(E) and working(W) days in Poland (MW) [8].

Shapes of winter and summer load profiles between years are pretty similar, however, the load has changed in the absolute values (Fig. 2). Particularly, it has increased much during summertime what can be attributed to the wide-spread use of air conditioning installations.

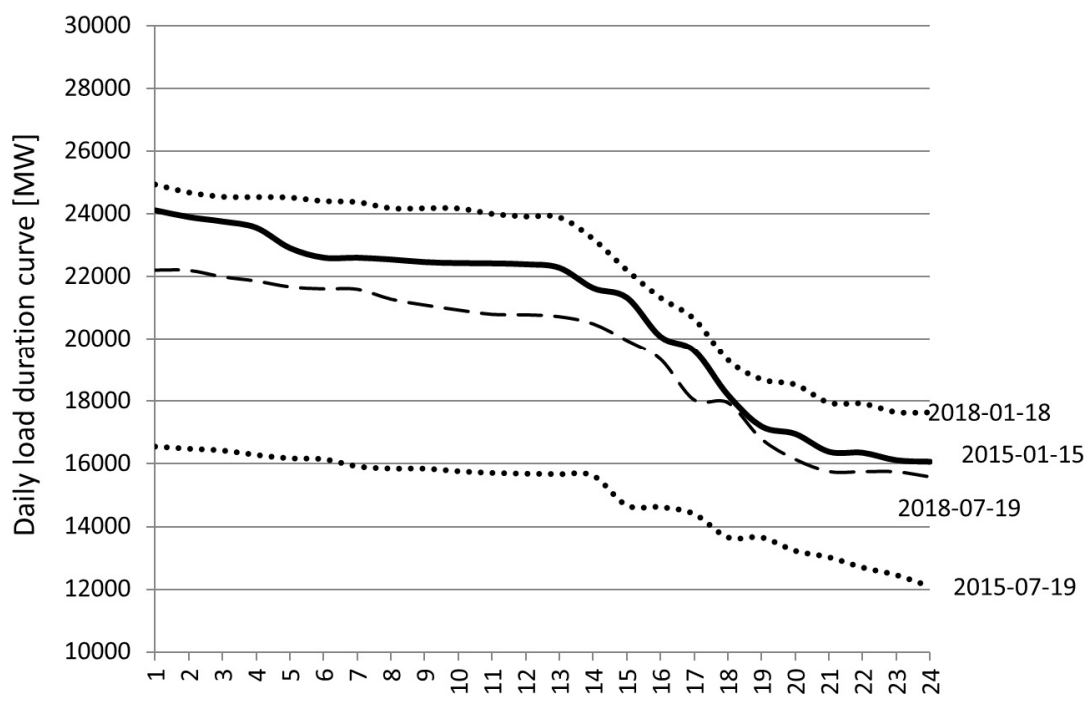

Fig. 2. Load curves for selected winter and summer days in Poland (MW) [8].

The differences between years can be linked to the economic growth. GDP has increased in these years more than $10 \%$ in total so much higher the energy demand. Consequently, energy intensity has decreased. Smaller fluctuation in daily loads should be beneficial for the power generators. However, the problem arises from intermittent wind generation. In case of Poland it has still a marginal impact. In the quoted days the power generation from wind was approximately $10 \%$ of total. But in Germany, for instance, situations happen when only wind generation is sufficient to balance the demand. This forces classical - coal generators to sell power at negative prices to maintain installations running for technical reasons. 
The monthly demands could be well estimated using econometric formulas as presented below for two different periods of time i.e. 1990s and 2000s. The equation based on the data from June 1992 to December 1997 is:

$$
\mathrm{MEC}=10294-215 \text { Temp }+25 \mathrm{IAI} ; \quad \mathrm{R}^{2}=1
$$

where:

MEC - monthly electricity consumption (MWh)

Temp - average monthly temperature ${ }^{\circ} \mathrm{C}$,

IAI - industry activity indicator \% relative to 1992.

Equation derived from the data: May 2013 - October 2017 is:

$$
\begin{aligned}
\mathrm{MEC}= & -1698+33 \mathrm{IAI}-118 \mathrm{Temp}+417 \text { Days }+30 \mathrm{CDD}+ \\
& -666 \mathrm{M} 345+706 \mathrm{D} 2017 \mathrm{M} 01-646 \mathrm{DD} 2014 \mathrm{M} 06 ; \quad \mathrm{R}^{2}=0.93
\end{aligned}
$$

where:

Days - number of days in the month,

CDD - cooling degree days,

M345 - dummy variable; 1 for March, April, May; 0 for other months,

D2017M01, D2014M06 - dummy variables, 1 for respective years and months.

Dummy variables in the second equation were used to catch exceptional deviation which occur for non-identified reasons. Also the deviation for March to May data is not explainable, but occurs and is statistically significant. Variable representing cooling degree days correspond to power consumption by air conditioning installations. The equations prove that the factors affecting energy consumption have changed and their set is growing corresponding to increasing complexity and patterns of energy use. For the development of energy system studies it should be assumed that the load pattern will be changing towards more linear form with less distinguishable peak and base periods. Smart metering and energy costs reduction opportunities should foster customers to change their behaviour leading to more power consumption in the low price periods. Also growing use of air conditioners should diminish the difference between summer and winter consumption patterns. Such changes flatten the system load curve what could be regarded as beneficial for the classical generators. However, because of the intermittent must-run RES generation, their role is moving towards balancing of the residual load i.e. the difference between the total system load and RES supplied power (which will now variate depending on RES supply fluctuations).

\subsection{The role of renewable energy sources}

Transition of the global energy system from the one developed during the era of industrialization has already started in the second part of the last century [9]. The main drivers for this transition have been mainly the will of countries to become more energy independent after oil crises in 1970s and also mitigation of the climate change. The accidents in nuclear power plants have led many countries to nuclear phase-out $[10,11]$. Thus practically only renewables remained a solution that could have fulfilled these requirements. Consequently, to bring the RES costs down to the competitive levels they have obtained a strong financial support for many years [2]. This has led, at first, to rapid development of the onshore wind, then photovoltaics and also offshore wind. At present, there are examples of offshore wind generation investments, which do not claim any support. The reasons are: firstly lower investment costs due to the learning processes, 
secondly the availability factor, in this case about $70 \%$, i.e. 6000 hours of full load, while for onshore availability factor is typically $20 \%, 1500-2000$ hours per year. Offshore generation is additionally more stable. The second most popular form of RES photovoltaics - has some advantages. The weather reports in this case are quite reliable, thus giving more certain supply forecasts. Also the sun operation and power generation profile are well matched with the system load e.g. perfect correlation exists with air conditioning. The example of daily generation profile employing renewables is presented in Fig. 3.

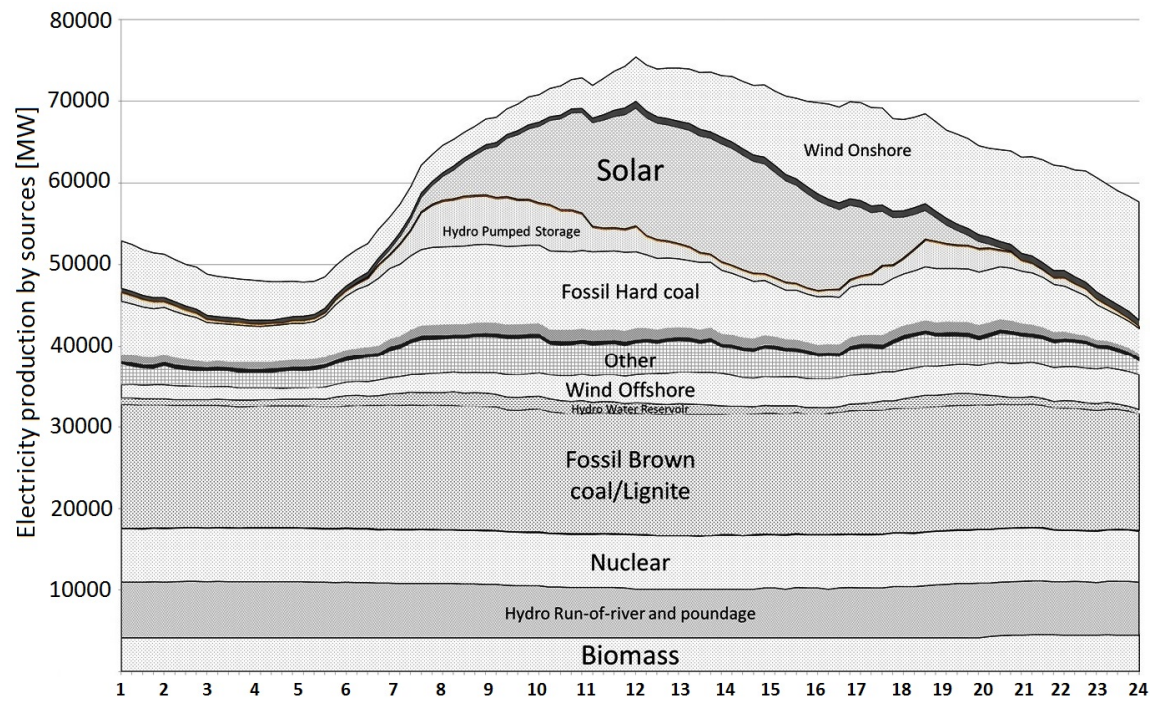

Fig. 3. Daily electricity production by sources (MW), Germany 16.05.2018. Source: ENTSOE.eu

The figure confirms the positive role of photovoltaics in balancing the peak load. The generators with controllable production have been placed in the lower part of the figure as base-load generators. They do not change much production over the day. The final system balancing is done with the use of hydro power stations.

\subsection{E-mobility}

There is a common opinion that the development of electric cars will have substantial impact on energy sector [12]. However, this is not proved by relevant studies. Fig. 4 presents global sales of new cars in the horizon of 2050. Classical gasoline and diesel cars sales should decrease shortly after 2020. Then dominating vehicles are gasoline hybrid cars which are subsequently replaced by pure electric cars (Battery Electric Vehicles-BEVs) after 2035. Finally in 2050 shares of hybrid and electric plus fuel cell cars are comparable. This proves that gasoline will still be used as fuel in transport in the future. The share of BEVs reaches only about $20 \%$ in 2050 . 


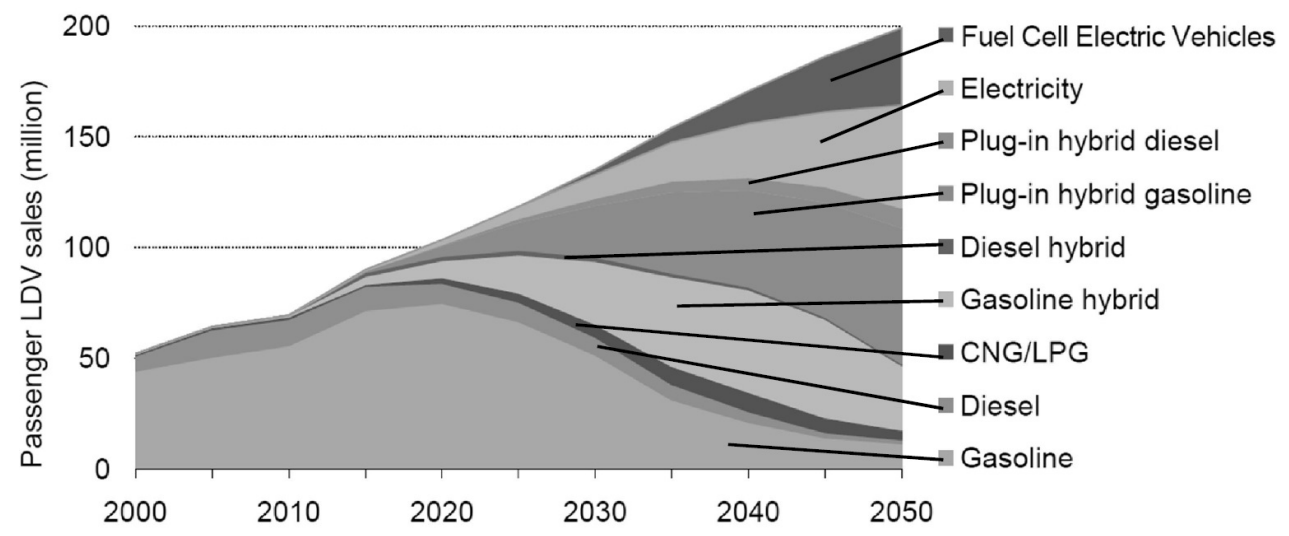

Fig. 4. Global light duty vehicles sales [13].

The other problem is how much electricity the cars will consume. Assuming $150 \mathrm{Wh} / \mathrm{km}$ consumption of electricity [14], gives $2250 \mathrm{kWh}$ per year with $15000 \mathrm{~km}$ annual mileage. The Polish program for electro-mobility assumes 1 million electric cars in 2025 what gives consumption of some $2.25 \mathrm{TWh}$ per year. This approximation shows that ambitious program will lead to practically $1.5 \%$ of national annual electricity consumption. In long term this share should increase, but it seems never to be important. Regulation and controlling of the charging process might be relevant. Adequate electricity price signals for the final users are necessary to avoid negative impacts on the system load i.e. charging during peak loads. But some benefits could be expected from use of electric cars as a means for short term electricity storage: load during low load night period and unload in peak of a day.

\section{Future electricity generation mix in Poland}

Poland has a long tradition of using hard coal and lignite for power generation. The current global climate policy, which requires substantial cuts in $\mathrm{CO}_{2}$ emissions constitutes a big challenge for the Polish carbon-intensive power industry. The forecasted prices of $\mathrm{CO}_{2}$ emission allowances on the ETS market (EUAs) could exceed 100 EUR after 2035. Once compared to the electricity generation costs in coal-based power plant, which at present without $\mathrm{CO}_{2}$ fee equals ca. 40 EUR, the inclusion of carbon cost would result in tremendous increase of overall generation costs [15]. In fact this is exactly why the EAUs prices need to be so high as to make future investment in fossil fuel-based generation unprofitable and simply to avoid such investments. The climate policy goal is the reduction of $\mathrm{CO}_{2}$ emissions to the atmosphere. Hence, if the economically viable solutions were commercially available to capture $\mathrm{CO}_{2}$ from the stream of flue gases and to store (CCS) or utilize (CCU) it - such solution should also be taken into account. There is no doubt that the energy system transition towards renewable energy sources has begun. However, it will be probably stretched out into a few decades during which fossil fuels will still dominate in the global energy mix. Can CCS or CCUs systems play a role in this transient period in reduction of $\mathrm{CO}_{2}$ emissions to the atmosphere? Will coal-based power generation still dominate in Poland in the future? To answer this question several energy scenarios were reviewed as regards the future Polish electricity generation mix. These included: the EP2050 - the main scenario considered in the draft of the Polish Energy Policy till 2050 [16], two EU Reference Energy scenarios (from 2013 [17] and 2016 [18]) and two 
scenarios modelled by the Authors with the use of TIMES-PL energy-economic model $[19,20]$. The respective quantitative data for years 2030 and 2050 are presented in table 1 .

Table 1. Gross electricity generation [TWh] for different scenarios. EP2050 - the main scenario considered in the draft of the Polish Energy Policy till 2050. EU-REF'13 and EU-REF'16 are the EU Reference Energy scenarios elaborated with the use of the PRIMES model. TIMES-PL1 and TIMES-PL2 were elaborated by the Authors with the use of the TIMES-PL model.

\begin{tabular}{|l|r|r|r|r|r|r|r|r|r|r|}
\hline Scenario: & \multicolumn{2}{|c|}{ EP2050 } & \multicolumn{2}{c|}{ EU-REF'13 } & \multicolumn{2}{c|}{ EU-REF'16 } & \multicolumn{2}{|c|}{ TIMES-PL1 } & \multicolumn{2}{c|}{ TIMES-PL2 } \\
\hline $\begin{array}{l}\text { Fuel } \\
\text { type: }\end{array}$ & 2030 & 2050 & 2030 & 2050 & 2030 & 2050 & 2030 & 2050 & 2030 & 2050 \\
\hline Solids & 117.1 & 84.8 & 117.9 & 135.7 & 132.1 & 63.6 & 141.4 & 116.9 & 142.5 & 62.1 \\
\hline Gas & 12.0 & 20.4 & 16.3 & 20.3 & 30.2 & 41.7 & 5.7 & 5.7 & 4.7 & 48.9 \\
\hline Nuclear & 23.3 & 43.2 & 48.6 & 74.1 & 0.0 & 69.3 & 0.0 & 40.9 & 0.0 & 49.3 \\
\hline RES & 51.9 & 73.2 & 36.8 & 49.5 & 40.4 & 70.5 & 47.4 & 74.1 & 47.4 & 74.3 \\
\hline Other & 1.4 & 1.4 & 0.3 & 0.5 & 0.5 & 0.3 & 2.9 & 2.9 & 2.9 & 2.9 \\
\hline Total & 205.7 & 223 & 219.9 & 280.1 & 203.2 & 245.4 & 197.4 & 240.5 & 197.5 & 237.5 \\
\hline
\end{tabular}

As one can see the scenarios with highest shares of electricity generated from coal (solids) are the EU-REF'13 and TIMES-PL1. These scenarios were elaborated in the spirit of optimism as regards the CCS concept prevailing in the first decade of 2000s. As a reminder, in that period the Carbon Capture and Storage (CCS) Directive was introduced to make every newly built coal power plant be CCS ready. Additionally, to accelerate the development of CCS, six demonstration projects were granted 1 billion EUR of financial assistance from the European Energy Programme for Recovery (EEPR) adopted by the European Parliament in July 2009. One of them considered a post-combustion capture, transportation and geological storage from the $858 \mathrm{MW}$ unit of the Polish brown coal power plant in Bełchatów. On the top of that, to support the construction and operation of up to 12 carbon capture and storage demonstration plants by 2015 a special financing mechanism called "NER300" has been established. This optimism was also reflected in the EU Energy Roadmap 2050 from 2011, in which the least costs decarbonisation scenario included large shares of electricity generated in CCS-equipped plants. Over time, however, this optimism has gradually dropped. The main reasons have been financial viability as well as lack of social acceptance for $\mathrm{CO}_{2}$ transport and storage - as in case of Bełchatów project that was finally abandoned in 2013. This is also reflected in newer scenarios like the EU Reference 2016, EP2050, or second TIMES-PL scenario where the CCS application has been limited. To sum up - the use of coal for power generation with high carbon prices will depend on the commercial availability of CCS/CCU technologies and this, as explained above, is uncertain. This notwithstanding, even in the most CCS-promising scenarios presented in Tab. 1 the relative share of electricity generated from coal does not exceed $50 \%$ in 2050 while in others it rather goes much below $30 \%$.

\section{Conclusions}

Without doubt an important transition of the global energy system has begun. A new paradigm was established at the end of the last century in which renewables are foreseen as the most favourable energy source for the future. However, this transition will have rather evolutionary character and will be probably stretched out into few decades during which fossil fuels will still dominate in the global energy mix. Adaptation to this new paradigm 
could constitute a challenge but also an opportunity for countries that at present are fossil fuel based - such as Poland. The critical factors influencing the future development of the Polish power sector have been discussed in this paper. In the Authors opinion global climate policy, which requires substantial cuts in $\mathrm{CO}_{2}$ emissions, support given to renewables as well as the ongoing liberalization and market coupling are the decisive factors in the current transitions of the power sectors. The analysed scenarios revealed the importance of the assumptions on the development of nuclear power (acceptance vs. nuclear phase-out) as well as the commercial availability of the CCS/CCU technologies. From the regulatory point of view liberalization of the electricity markets resulted in lowering the electricity price for final users. However, with the current market design, investment support given to renewables and their nearly zero short-run marginal costs make them ranked first in the merit order. Consequently, the classical units are pushed away and left without necessary income to renew their controllable capacities. To overcome the problem new market instruments were introduced in the form of the capacity market which should compensate for the price uncertainties for the power investors. From the energy system point of view both demand- and supply- sides encounter changes. The shape of load duration curve becomes more of linear nature with hardly observable peak and low demands levels. The whole curve is moving upward meaning that the demand is growing over time. This is particularly visible in summertime due to the growing use of air conditioning and proved by the presented econometric formulas. On the supply side, due to the growing RES capacities, the operation of traditional thermal units has become more and more irregular as now they need to cover only a residual load. This problem is mostly caused by onshore wind as photovoltaics can play a positive role in balancing the peak load during the day and offshore wind is more of the baseload type. These problems can be solved in the future by enhancing the system flexibility and by large-scale energy storage that might become commercially available. Finally, the use of coal for power generation with high carbon prices will also depend on the commercial availability of CCS/CCU technologies but this is uncertain. For Poland even in the most CCS-promising scenarios revised in the paper a relative share of electricity generated from coal does not exceed $50 \%$ in 2050 while in others it rather goes much below $30 \%$.

\section{References}

1. A. Limura, J. S.Cross, Utilities Policy 54, 96-106 (2018)

2. V. Lauber, Energy Policy 32, 1405-1414 (2004)

3. A. Modzelewski, Napędy i Sterowanie 9, 106-112 (2014)

4. J. Michaelis et al., 14th International Conference on the European Energy Market (EEM), doi: 10.1109/EEM.2017.7981983, 1-5 (2017)

5. P. C. Bhagwat et al., Utilities Policy 48, 76-91 (2017)

6. W. Suwala, A. Wyrwa, M. Pluta, E3S Web of Conferences 14, 01001 (2017)

7. R. Grossa, R. Hannaa,A. Gambhirb, P. Heptonstalla, J. Speirsc, Energy Policy 123, 682-699, (2018)

8. https://www.pse.pl/dane-systemowe/funkcjonowanie-kse/raporty-dobowe-z-pracykse/zapotrzebowanie-mocy-kse (Accessed: 10 Sept 2018)

9. C. Zou, Q.Zhao, G, Zhang, B. Xiong, Energy revolution: From a fossil energy era to a new energy era, Natural Gas Industry B 3, 1-11, (2016)

10. K. S. Rogge, P. Johnstone, Energy Research \& Social Science 33, 128-137 (2017)

11. S. Park, W. Jung, T. Kim, S. T. Lee, Nuclear Engineering and Technology 48, 559-571 (2016)

12. Jesień L., Kurtyka M., New Electrcity and New cars. The Future of European Energy Doctrine, CeDeWu (2016) 
13. https://image.slidesharecdn.com/irelandev-120711073758-phpapp02/95/the-role-ofelectric-vehicles-in-a-clean-energy-future-iea-executive-director-5728.jpg?cb=1342077798 (Accessed: 10 Sept 2018)

14. Chiara Fiori , Kyoungho Ahn a,1, Hesham A. Rakha, Applied Energy 168, 257-268 (2016)

15. U. Bariss, E. Avenitis, G. Junghans, D. Blumberga, Energy Procedia 95, 58-65 (2016)

16. Ministry of Economy, Annex 2 to the Energy Policy of Poland until 2050 (2015)

17. European Commission, Energy, transport and GHG emissions trends to 2050. Reference scenario (2013)

18. European Commission, Energy, transport and GHG emissions trends to 2050. Reference scenario (2016)

19. A. Wyrwa, A. Szurlej, L. Gawlik, W. Suwala, Journal of Power Technologies 95, 100$106(2015)$

20. W. Suwala, T. Olkuski, A. Wyrwa, IOP Conf. Ser.: Mater. Sci. Eng. 268 (2017) 